\title{
The Metabolic Syndrome of $\omega 3$-Depleted Rats. X: Comprehensive View
}

\author{
Willy J. Malaisse ${ }^{1, *}$, Mirjam Hacquebard ${ }^{2}$, Ying Zhang $^{1}$, Nurdan Bulur ${ }^{1}$, Abdullah Sener ${ }^{1}$ and \\ Yvon A. Carpentier ${ }^{2}$
}

Laboratories of Experimental ${ }^{1}$ Hormonology and ${ }^{2}$ Surgery, Université Libre de Bruxelles, Brussels, Belgium

\begin{abstract}
The present report complements recent publications on the occurrence of a metabolic syndrome in rats deprived of a dietary supply of long-chain polyunsaturated $\omega 3$ fatty acids and on the attempt to correct the resulting metabolic and hormonal defects by exposure of the $\omega 3$-depleted rats to a diet enriched with flaxseed oil rich in $\alpha$-linolenic acid

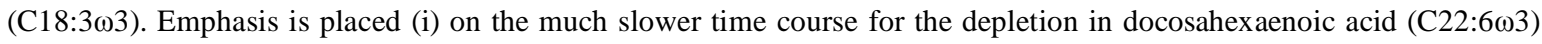

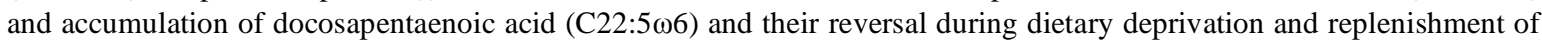
$\omega 3$ fatty acids in brain phospholipids, as opposed to liver or intestinal phospholipids, (ii) on the role of circulating phospholipids in the transfer of $\mathrm{C} 22: 6 \omega 3$, synthesized from $\mathrm{C} 18: 3 \omega 3$ in hepatocytes, from the liver to the brain in the rats deprived of a dietary supply of $\omega 3$ fatty acids, and (iii) on the unfavorable effect of an increase in the total lipid content of the diet from 5 to $10 \%(\mathrm{w} / \mathrm{w})$ in the perspective of the correction of liver steatosis and visceral obesity in the $\omega 3$-depleted rats.
\end{abstract}

Keywords: Phospholipids in long-chain polyunsaturated $\omega 3$ fatty acid-depleted rats, soya, sunflower and flaxseed oils, liver, intestinal and brain phospholipids.

\section{INTRODUCTION}

The primary aim of the present series of reports [1-9] was to investigate whether normal rats exposed from the $6^{\text {th }}$ week after birth and for the ensuing 3 to 7 months to a diet deprived of long-chain polyunsaturated $\omega 3$ fatty acids would represent a suitable model to reproduce those features of the metabolic syndrome previously documented in second generation $\omega 3$-depleted rats $(\omega 3 \mathrm{D})$. The present approach was indeed considered to simulate more closely the situation found in human subjects with a deficient dietary supply of $\omega 3$ fatty acids. It should not be ignored, however, that, to a certain extent at least, human subjects born from parents with an insufficient dietary supply of $\omega 3$ fatty acids may soon conceivably become somehow comparable to first and, possibly later, second generation $\omega 3 \mathrm{D}$ rats.

In addition, our investigations also dealt with the changes in several metabolic and hormonal variables recorded after restoration of an $\omega 3$-rich diet in the previously $\omega 3 \mathrm{D}$ rats, i.e. when they were exposed to their $\omega 3$-depleted diet containing $5 \%(\mathrm{w} / \mathrm{w})$ sunflower oil now enriched with another $5 \%$ (w/w) flaxseed oil.

The present report provides an overall view of these investigations, with emphasis on selected aspects, such as the interrelation between distinct variables, not yet considered in our prior articles in this series.

\section{MATERIALS AND METHODS}

Two distinct sets of experiments were conducted in the framework of the present study (Table $\mathbf{1}$ ).

*Address correspondence to this author at the Laboratory of Experimental Hormonology, Université Libre de Bruxelles, 808 Route de Lennik, B-1070 Brussels, Belgium; Tel: 32-2-5556237; Fax: 32-2-5556356;

E-mail: malaisse@ulb.ac.be
In the first set of experiments, eight groups of 5-6 rats each, all 6 weeks-old at the onset of the experiments, were examined. They included control animals sacrificed after either 3 or 7 months exposure to a diet containing soya oil ( 5 $\%$, w/w) and $\omega 3 \mathrm{D}$ rats examined after 3 or 7 months exposure to an $\omega 3$-poor diet containing sunflower oil $(5 \%$, w/w). Two further groups of control animals were exposed after the first 7 months and for the ensuing 4-5 weeks to the same soya diet enriched with either $5 \%$ soya oil or $5 \%$ flaxseed oil, so that the total lipid of the diet was increased to $10 \%$. Likewise, two further groups of $\omega 3 \mathrm{D}$ rats were exposed after the first 7 months and for the ensuing 2 or 4-5 weeks to their sunflower oil-containing diet eventually enriched with $5 \%$ flaxseed oil. At sacrifice, the fatty acid pattern of liver and brain phospholipids and triglycerides, as well as fatty acid pattern of duodenal, jejunal, caecal and colic phospholipids was analyzed. The body weight, the parametrial adipose tissue weight, the plasma glucose and insulin concentrations were also recorded in all these animals.

In the second set of experiments, 3 groups of 6 rats each were examined. They included two groups of control rats first exposed for 7 months to the diet containing $5 \%$ soya oil and then exposed for about 20 days to the same diet enriched with $5 \%$ of either soya or flaxseed oil, and one group of $\omega 3 \mathrm{D}$ rats first exposed for 7 months to the diet containing 5 $\%$ sunflower oil and then exposed for about 20 days to the same diet enriched with $5 \%$ flaxseed oil. In addition to the characterization of the fatty acid pattern of liver phospholipids and triglycerides, time-related changes in body weight and measurement of plasma glucose and insulin concentrations, the food intake of these animals was also monitored over the last 7 days prior to and 14 days after the switch in diet.

For the sake of comparison, attention is also drawn to the results collected in prior studies in 3 groups of second gen- 
Table 1. Symbols, Dietary Schedule and Number of Animals in the 15 Groups of Female Rats Considered in this Report

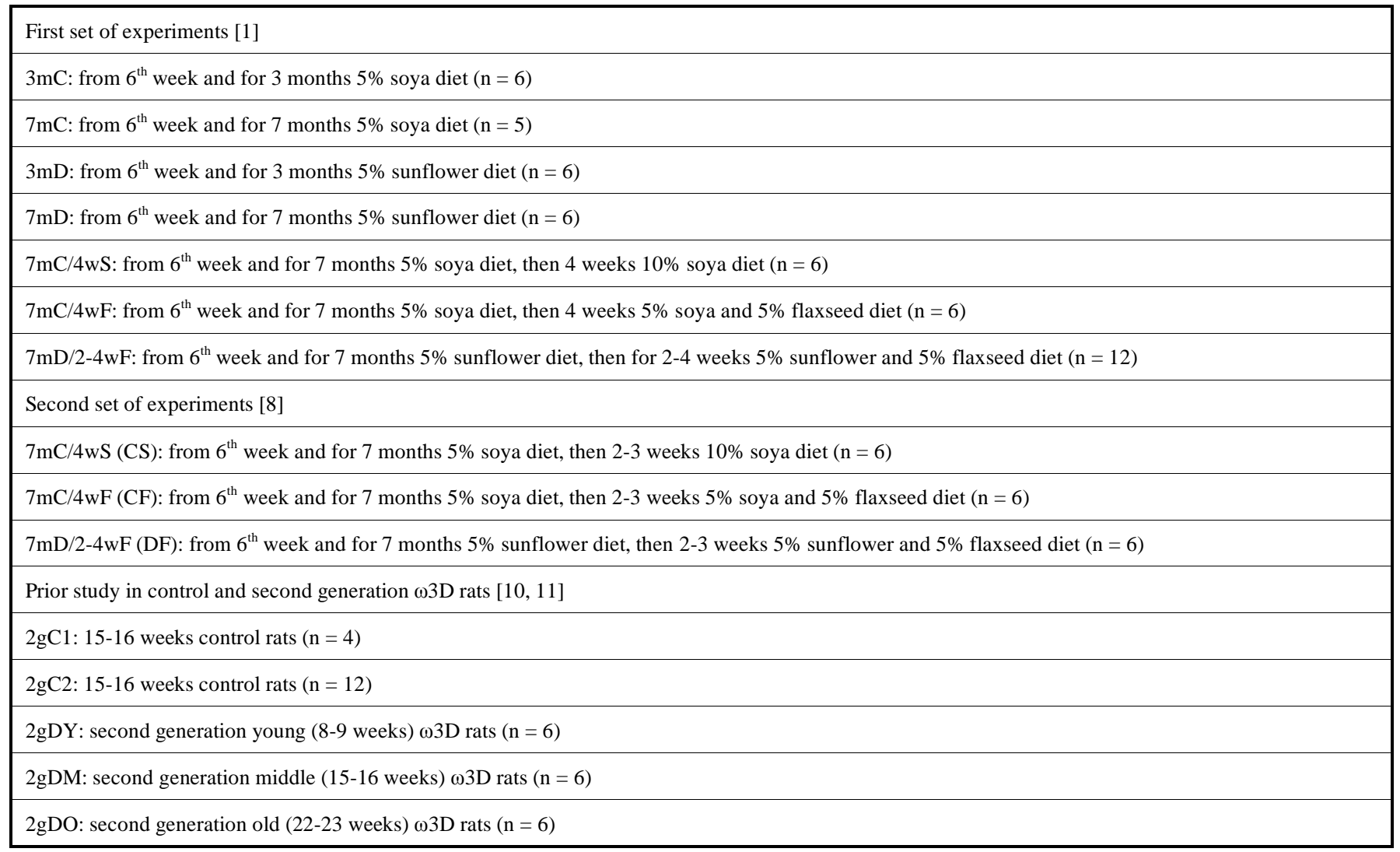

eration $\omega 3 \mathrm{D}$ rats of increasing ages $(8-9,15-16$ and $22-23$ weeks) and in 2 corresponding groups of 4 and 12 control animals with a mean age comparable to the mean age of the $\omega 3 \mathrm{D}$ rats $[10,11]$.

The methods used for the extraction of lipids, their separation by thin-layer chromatography and the determination of their fatty acid pattern [1], and for the measurement of body weight and food intake [9] are defined in the cited references.

All results are presented as mean values $( \pm$ SEM) together with the number of individual determinations (n) or degree of freedom (df). They are expressed either in absolute terms or relative to the mean value found within each separate group of rats. The latter results are here mentioned as normalized data. The statistical significance of differences between mean values [1], the correlation between distinct variables and the comparison of regression lines by covariance analysis [12] were conducted as described in the cited references.

\section{RESULTS AND COMMENTS}

\section{Liver Phospholipids and Triglycerides}

The characterization of the fatty acid pattern of liver phospholipids and triglycerides provided several major pieces of information.

First, it allowed to characterize the time course of changes in several variables as resulting from either the exposure of the rats to a diet containing $5 \%$ of sunflower oil and, as such, deprived of long-chain polyunsaturated $\omega 3$ fatty acids or the exposure of the $\omega 3 \mathrm{D}$ rats to the same diet enriched with another $5 \%$ of flaxseed oil rich in C18:3 03 . For instance, Fig. (1) documents that both the C22:6 13 and C22:5 $\omega 6$ content of liver phospholipids reached a close-tosteady-state value within either 3 months of dietary $\omega 3$ deprivation or within 2 weeks of exposure of the $\omega 3 \mathrm{D}$ rats to the diet rich in $\mathrm{C} 18: 3 \omega 3$.

Second, a further potential interest of the liver data consisted in the exploration of possible cause-to-effect links, as assessed by correlation between distinct variables. For instance, Fig. (2) illustrates the highly significant negative correlation $(\mathrm{r}=-0.7433 ; \mathrm{n}=23 ; \mathrm{p}<0.001)$ found between the C16:107/C16:0 ratio in liver phospholipids and their $\mathrm{C} 22: 603$ relative weight content in the 23 rats examined in the first study during the first 7 months of the experiments. Such a correlation reflected mainly, however, a group difference between control and $\omega 3 \mathrm{D}$ rats. Indeed, no significant correlation was anymore observed $(r=+0.2447 ; n=23, p>$ 0.1 ) in these 23 rats when the individual results for the two variables under consideration were expressed as normalized values, i.e. relative to the mean corresponding value derived from all individual measurements made within the same group of rats with the same age and same nutritional status [13]. Moreover, as documented in Table 2, when the control rats were eventually exposed for 4-5 weeks to either a soybean or flaxseed oil-enriched diet, a modest decrease in the liver phospholipid $\mathrm{C} 22: 6 \omega 3$ content coincided with a paradoxical decrease of the $\mathrm{C} 16: 1 \omega 7 / \mathrm{C} 16: 0$ ratio in the same liver phospholipids. Even more strikingly, the restoration of 

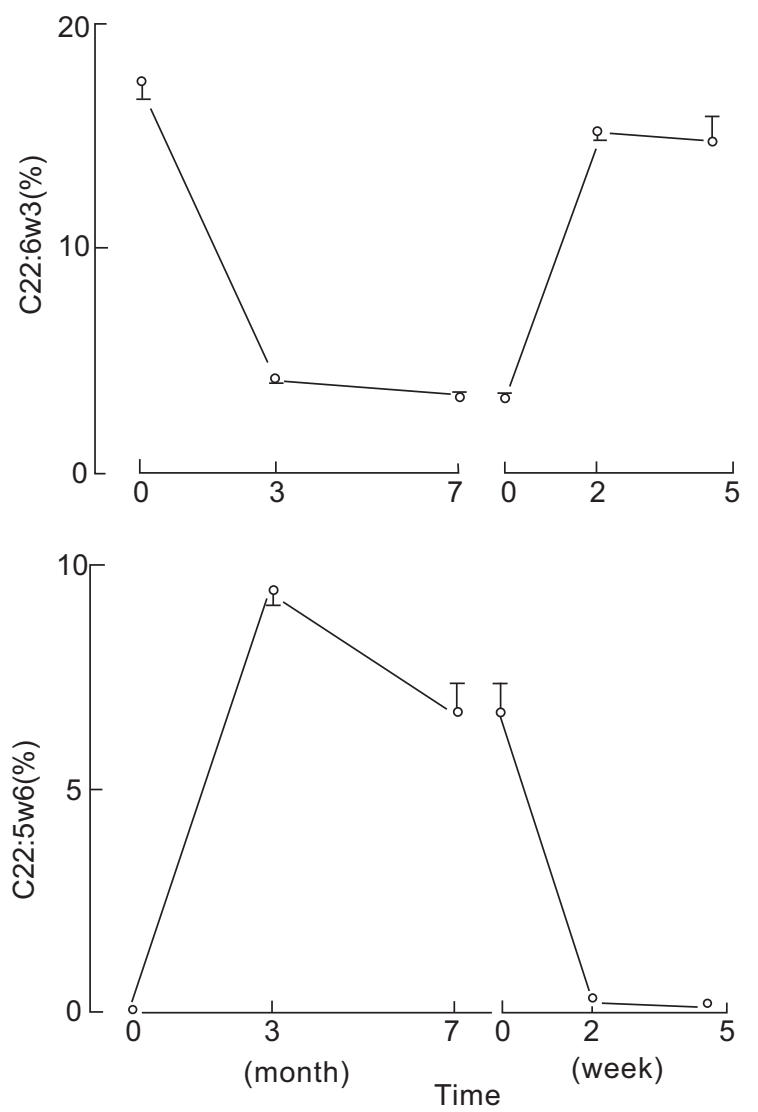

Fig. (1). Time course for the changes in the $C 22: 6 \omega 3$ and $C 22: 5 \omega 6$ relative weight content of liver phospholipids over 7 months exposure of normal rats to a diet containing $5 \%$ sunflower oil (left) and after 2 to 4-5 subsequent weeks of exposure to the same diet enriched with $5 \%$ flaxseed oil (right). Mean values ( \pm SEM) refer to 6 individual determinations except at time zero in the left panels, in which case the results refer to 11 measurements made during the first 7 months of the present experiments in control animals exposed to a diet containing $5 \%$ soya oil.

a normal value for the liver phospholipid C22:6 $\omega 3$ content in the $\omega 3 \mathrm{D}$ rats exposed for 2 and 4-5 weeks to a flaxseed oilenriched diet failed to be associated with any significant change in the high values for the $\mathrm{C} 16: 1 \omega 7 / \mathrm{C} 16: 0$ ratio otherwise found in the $\omega 3 \mathrm{D}$ rats. A comparable situation prevailed in the case of liver triglycerides, except that, in sharp contrast with the results recorded in liver phospholipids, the relative weight content of $\mathrm{C} 22: 6 \omega 3$ in hepatic triglycerides remained far below the normal level in the $\omega 3 \mathrm{D}$ rats eventually exposed to the flaxseed oil-enriched diet (Table 2). The latter situation is attributable to the absence of any detectable amount of $\mathrm{C} 22: 6 \omega 3$ in the lipids of the diet containing $5 \%$ (w/w) of both sunflower and flaxseed oil. As a matter of fact, advantage was taken of the comparison between the diet content in selected $\omega 3$ fatty acids and the changes recorded in their abundance in liver triglycerides to estimate the food intake after the switch in diet (see below).

\section{Intestinal Phospholipids}

The first set of experiments also allowed to assess the effect of dietary manipulations on the fatty acid pattern of phospholipids in the duodenum, jejunum, caecum and colon.

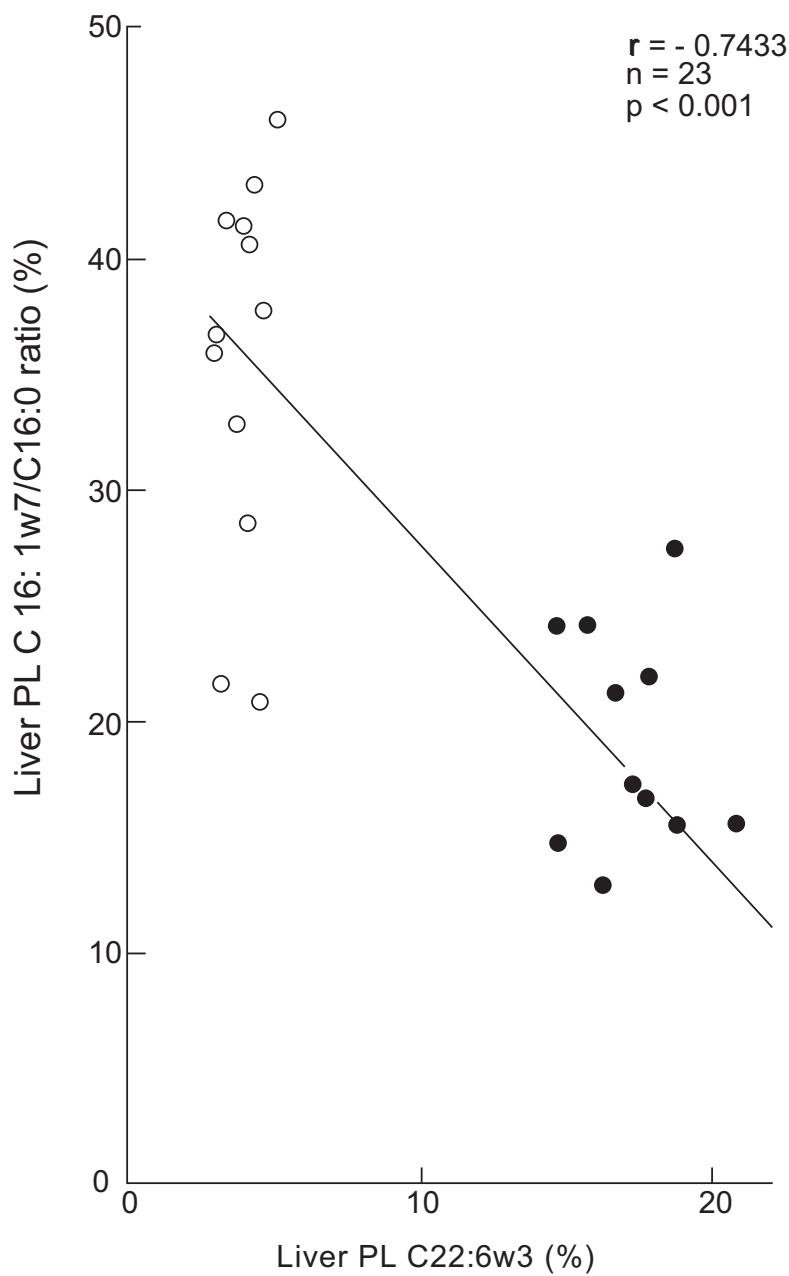

Fig. (2). Correlation between the liver phospholipid

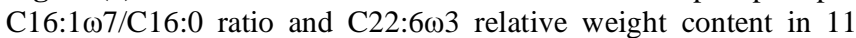
control rats maintained for 3 to 7 months to a diet containing $5 \%$ soya oil (closed circles) and $12 \omega 3$-depleted rats exposed for 3 to 7 months to a diet containing $5 \%$ sunflower oil (open circles). The oblique line corresponds to the correlation line (with a $\sqrt{\Sigma y^{2} / \Sigma x^{2}}$ slope).

The most relevant information emerging from these investigations in the framework of the present report may be summarized as follows.

The changes in the intestinal phospholipid content of long-chain polyunsaturated $\omega 3$ fatty acids provoked by the dietary manipulations were extremely rapid and severe (Fig. 3). In the $\omega 3 \mathrm{D}$ rats, the $\mathrm{C} 18: \omega 3, \mathrm{C} 20: 5 \omega 3$ and $\mathrm{C} 22: 5 \omega 3$ phospholipid content reached undetectable values within 3 months of exposure to the sunflower oil-containing diet in all, except one, of 54 separate determinations [4]. The C22:6 63 content of intestinal phospholipids, reached after 3 and 7 months of dietary $\omega 3$ deprivation values representing, respectively $25.1 \pm 3.2 \%(n=18)$ and $17.3 \pm 2.0 \%(n=24)$ of the mean corresponding values found at the same age and same level of the intestinal tract in the control animals. Likewise, within 2 weeks of exposure to a flaxseed oilenriched diet, the $\omega 3 \mathrm{D}$ rats displayed C18:3 $\omega 3, \mathrm{C} 20: 5 \omega 3$ and C22:5 $\omega 3$ relative weight content in intestinal phospholipids strikingly higher than the values otherwise found in control animals. Even the C22:6 63 relative weight content of intestinal phospholipids reached, at the same time, a mean value 


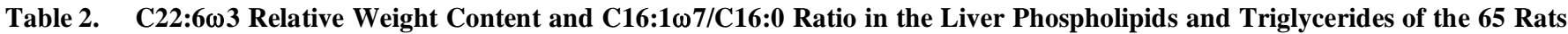
Examined in the Two Present Sets of Experiments

\begin{tabular}{|c|c|c|c|c|}
\hline Rats & \multicolumn{2}{|c|}{ Liver phospholipids } & \multicolumn{2}{|c|}{ Liver triglycerides } \\
\hline $3 \mathrm{mD} \& 7 \mathrm{mD}$ & $3.9 \pm 0.2(12)$ & $33.9 \pm 2.1(12)$ & $0.0 \pm 0.0(12)$ & $119.7 \pm 7.7(12)$ \\
\hline $7 \mathrm{mC} / 4 \mathrm{wS}$ & $15.1 \pm 0.5(12)$ & $13.9 \pm 2.4(12)$ & $4.3 \pm 0.2(12)$ & $64.7 \pm 10.2(12)$ \\
\hline $7 \mathrm{mD} / 2-4 \mathrm{wF}$ & $15.0 \pm 0.5(18)$ & $34.7 \pm 3.1(18)$ & $1.4 \pm 0.1(18)$ & $132.9 \pm 12.2(18)$ \\
\hline
\end{tabular}

${ }^{a} 3 \mathrm{mC} \& 7 \mathrm{mC}$ : control rats examined 3 and 7 months after the start of the experiments; $3 \mathrm{mD} \& 7 \mathrm{mD}: \omega 3 \mathrm{D}$ rats examined 3 and $7 \mathrm{months}$ after the start of the experiments; $7 \mathrm{mC} / 4 \mathrm{wS}$ and $7 \mathrm{mC} / 4 \mathrm{wF}$ : control rats eventually exposed for $4-5$ weeks to a soybean and flaxseed oil-enriched diet, respectively; $7 \mathrm{mD} / 2-4 \mathrm{wF}$ : $\omega 3 \mathrm{D}$ rats eventually exposed for 2 to $4-5$ weeks to a flaxseed oil-enriched diet.

representing $81.1 \pm 4.1 \%(n=24)$ of the mean corresponding reference values found at the same level of the intestinal tract in the control animals examined 7 months after the onset of the experiments [4]. As a matter of fact, a highly significant positive correlation $(\mathrm{r}=+0.9636 ; \mathrm{n}=16 ; \mathrm{p}<0.001)$ was found between the mean relative weight content of each of the four $\omega 3$ fatty acids in the different segments of the intestinal tract in the control and $\omega 3 \mathrm{D}$ rats both eventually exposed for 4-5 weeks to a flaxseed oil-enriched diet, the values found in the $\omega 3 \mathrm{D}$ rats averaging $88.3 \pm 5.1 \%(\mathrm{n}=96)$ of the corresponding values recorded for the same $\omega 3$ fatty acid at the same level of the intestinal tract in the control animals $(100.0 \pm 3.3 \% ; \mathrm{n}=96)$.

A comparable situation prevailed in the case of the longchain polyunsaturated $\omega 6$ fatty acids. To cite only one example, whilst no $\mathrm{C} 22: 5 \omega 6$ could be detected in any intestinal sample collected during the first seven months of the present experiments in control rats, the phospholipid relative weight content of this fatty acid reached within 3 months of dietary $\omega 3$ deprivation values close to those found after 7 months of dietary $\omega 3$ deprivation (Fig. 3). Moreover, when the $\omega 3 \mathrm{D}$ rats were exposed for 2 to $4-5$ weeks to the flaxseed oilenriched diet the $\mathrm{C} 22: 5 \omega 6$ relative weight content of intestinal phospholipids did no more exceed, respectively, $0.11 \pm$ $0.04 \%(\mathrm{n}=24)$ and $0.08 \pm 0.03 \%(\mathrm{n}=24)$, as compared $(\mathrm{p}$ $<0.001)$ to $2.17 \pm 0.18 \%(\mathrm{n}=24)$ in the $\omega 3 \mathrm{D}$ rats examined just before exposure to this diet.

Last, in the case of saturated and monodesaturated fatty acids, emphasis was placed not solely on differences in the relative weight content of the same fatty acid in distinct intestinal locations, as also documented in the case of both long-chain polyunsaturated $\omega 3$ and $\omega 6$ fatty acids, but also on distinct responses to the same dietary manipulation in the several intestinal segments. To cite only one example, in the duodenum and jejunum, no significant correlation $(\mathrm{r}=+$ $0.3456 ; \mathrm{n}=14 ; \mathrm{p}>0.1$ ) was found in the 8 groups of rats examined in this study between the mean values for the phospholipid content of 8 saturated and monodesaturated

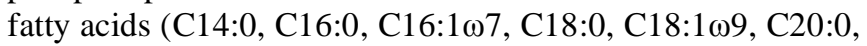
$\mathrm{C} 22: 0$ and $\mathrm{C} 24: 0$ ), expressed in each case relative to the content of the same fatty acids at the same intestinal level in the control animals sacrificed 7 months after the onset of the present experiments, on one hand, and the mean C22:603
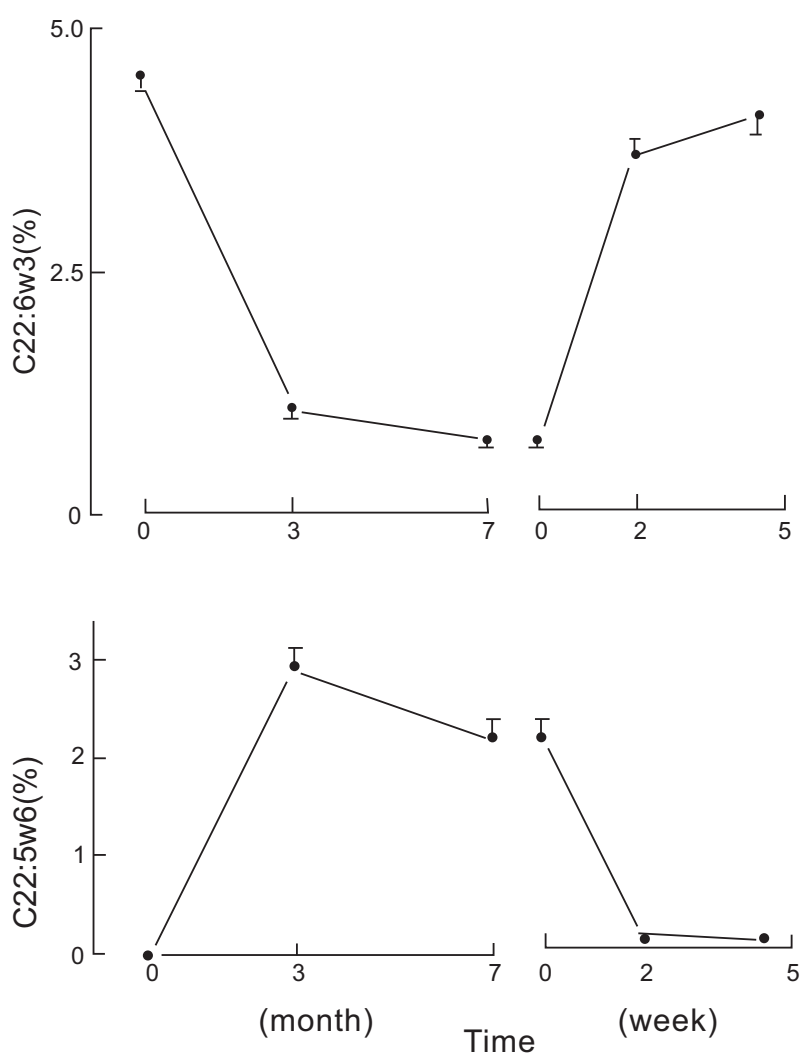

Fig. (3). Time course for the changes in the $C 22: 6 \omega 3$ and $C 22: 5 \omega 6$ relative weight content of intestinal phospholipids over 7 months exposure of normal rats to a diet containing $5 \%$ sunflower oil (left) and after 2 to $4-5$ subsequent weeks of exposure to the same diet enriched with $5 \%$ flaxseed oil (right). At time zero in the upper left panel, the results refer to 36 absolute values recorded at 4 levels of the intestinal tract (duodenum, jejunum, caecum and colon) during the first 7 months of the present experiments in control animals exposed to a diet containing $5 \%$ soya oil. The other results in the upper panels were first expressed relative to the mean control values recorded at the same intestinal levels in either control animals of the same age (left panel) or control rats examined 7 months after the onset of the experiments (right panel), and then converted to absolute values taking into account the mean absolute value indicated in the upper left panel at time zero $(4.50 \pm 0.13 \% ; n=36)$. In the lower panels, mean absolute values $( \pm$ SEM) refer to 36 measurements at time zero, 14 measurements at month 3 and 24 measurements thereafter. 
content of phospholipids found at the same intestinal location, and expressed relative to the mean overall value recorded for the same variable in the same 8 groups of rats, on the other hand (Fig. 4, left panel). In the caecum and colon, however, a comparable analytical procedure yielded a significant negative correlation $(\mathrm{r}=-0.6503 ; \mathrm{n}=16 ; \mathrm{p}<0.008)$ between the same two variables (Fig. 4, right panel). Covariance analysis confirmed that the slope of the regression line was significantly different in the proximal and distal segments of the intestinal tract [6]. Incidentally, the data illustrated in Fig. (4) are derived from 1,566 individual determinations concerning the relative weight content of selected fatty acids in intestinal phospholipids.

\section{Brain Phospholipids}

The time course of changes in relevant variables in brain phospholipids was vastly different from that recorded in the case of either liver or intestinal phospholipids. Indeed, as documented in Fig. (5), the same two variables as those considered in liver phospholipids (Fig. 1) and intestinal phospholipids (Fig. 3), i.e. the $\mathrm{C} 22: 6 \omega 3$ and $\mathrm{C} 22: 5 \omega 6$ relative content, demonstrated during the first 7 months of dietary $\omega 3$ deprivation and the subsequent 2 to 4-5 weeks of exposure to the flaxseed oil-enriched diet progressive changes, the values recorded after 7 months of dietary $\omega 3$ deprivation or after 45 weeks exposure to the flaxseed oil-enriched diet being, as a rule, significantly different $(\mathrm{p}<0.005$ or less) from those found, respectively, after only 3 months of dietary $\omega 3$ deprivation or after only 2 weeks exposure to the flaxseed oilenriched diet. Only the relative content of $\mathrm{C} 22: 6 \omega 3$ in brain

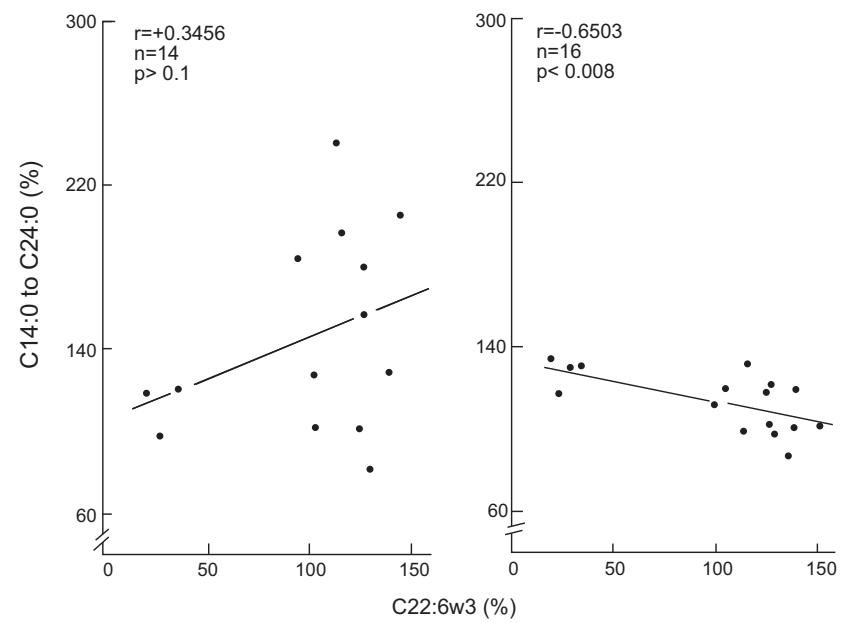

Fig. (4). Correlations between the $\mathrm{C} 22: 6 \omega 3$ relative weight content of intestinal phospholipids and the mean value for the relative weight content of 8 saturated and monodesaturated fatty acids

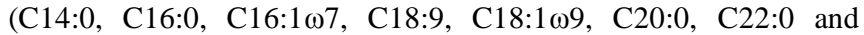
$\mathrm{C} 24: 0)$. The latter results are expressed relative to the content of the same fatty acids at the same intestinal level in the control animals examined 7 months after the onset of the present experiments, whilst the mean $\mathrm{C} 22: 6 \omega 3$ contents found at the same intestinal location are expressed relative to the mean overall value recorded for the same variable in the same 8 groups of rats. The left and right panels refer, respectively, to the data collected in the duodenum and jejunum and in the caecum and colon. The oblique lines correspond to the regression lines.
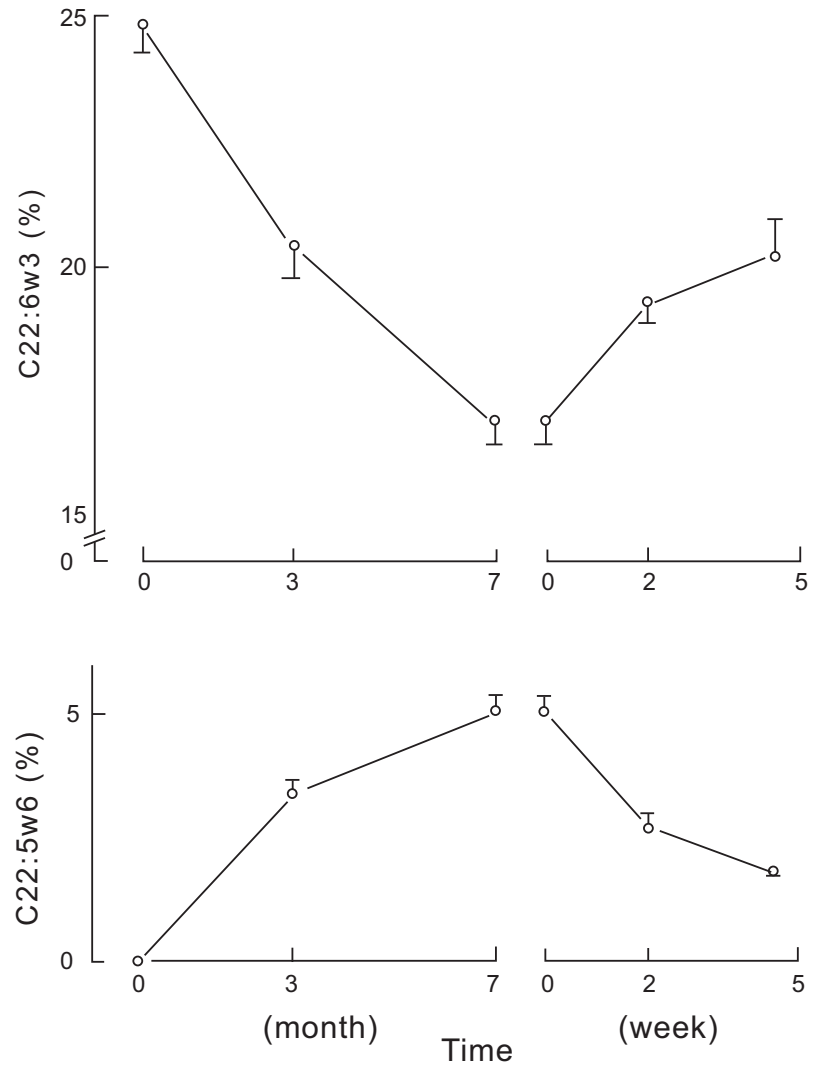

Fig. (5). Time course for the changes in the $\mathrm{C} 22: 6 \omega 3$ and $\mathrm{C} 22: 5 \omega 6$ relative weight content of brain phospholipids over 7 months exposure of normal rats to a diet containing $5 \%$ sunflower oil (left) and after 2 to 4-5 subsequent weeks of exposure to the same diet enriched with $5 \%$ flaxseed oil (right). Mean values ( \pm SEM) refer to 6 individual determinations except at time zero in the left panels, in which case the results refer to 11 measurements made during the first 7 months of the present experiments in control animals exposed to a diet containing $5 \%$ soya oil.

phospholipids failed to display a significant rise when comparing the results recorded in the $\omega 3$-depleted rats after 2 and 4-5 weeks exposure to the flaxseed oil-enriched diet. Nevertheless, in these $\omega 3 \mathrm{D}$ rats, the brain phospholipid content in $\mathrm{C} 22: 6 \omega 3(20.3 \pm 0.6 \% ; \mathrm{n}=6)$ and $\mathrm{C} 22: 5 \omega 6(1.8 \pm 0.1 \% ; \mathrm{n}$ $=6)$ alike remained both significantly different $(\mathrm{p}<0.001)$ after 4-5 weeks exposure to the flaxseed oil-enriched diet from the corresponding values otherwise recorded in control animals, i.e. $24.8 \pm 0.6 \%(\mathrm{n}=11)$ in the case of $\mathrm{C} 22: 6 \omega 3$ and readings close to the limit of detection in the case of C22:5 6 .

Table 3 provides further evidence for the more rapid response of the liver, as distinct from brain, to a dietary deprivation of long-chain polyunsaturated $\omega 3$ fatty acids. It indeed documents that the $\mathrm{C} 22: 6 \omega 3$ and $\mathrm{C} 22: 5 \omega 6$ relative weight contents of liver phospholipids were of the same order of magnitude in the rats deprived from the $6^{\text {th }}$ week after birth over the ensuing 7 months of a dietary supply of $\omega 3$ fatty acids and in $2^{\text {nd }}$-generation $\omega 3 \mathrm{D}$ rats. In the brain, however, the liver phospholipid C22:6 13 relative weight content was about 6 -fold higher in the zero-generation rats than in the $2^{\text {nd }}$-generation animals, whilst that of C22:5 16 was 3-fold higher in the latter animals than in the former rats. 


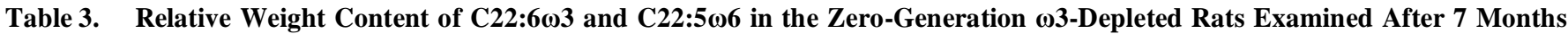
Exposure to a Diet Containing $5 \%$ Sunflower Oil, and in Second-Generation w3-Depleted Rats (8-9 Weeks Old) of Same Gender

\begin{tabular}{|c|c|c|c|c|}
\hline \multirow{2}{*}{$\begin{array}{c}\text { Fatty Acids } \\
\text { Rats }\end{array}$} & \multicolumn{2}{|c|}{$\mathrm{C} 22: 6 \omega 3(\%)$} & \multicolumn{2}{|c|}{ C22:506 (\%) } \\
\hline & Zero-generation & $2^{\text {nd }}$-generation & Zero-generation & $2^{\text {nd }}$-generation \\
\hline Brain & $16.0 \pm 0.5(6)$ & $2.9 \pm 0.1(6)$ & $5.0 \pm 0.3(6)$ & $15.1 \pm 0.4(6)$ \\
\hline
\end{tabular}

Once again, significant correlations were found between distinct variables relative to the brain phospholipid fatty acid total content and pattern, suggesting that the differences between control and $\omega 3 \mathrm{D}$ rats represent the outcome of a tightly coordinated sequence of events initiated by the insufficient supply of long-chain polyunsaturated $\omega 3$ fatty acids. For instance, even after normalization of the individual measurements relative to their mean value within each group of rats, such significant correlations were found between the total fatty acid content of brain phospholipids and their $\mathrm{C} 20: 4 \omega 6$ relative content, the $\mathrm{C} 24: 0$ and $\mathrm{C} 20: 4 \omega 6$ relative content, the $\mathrm{C} 18: 1 \omega 9$ and $\mathrm{C} 20: 4 \omega 6$ relative content, or the $\mathrm{C} 16: 0$ and $\mathrm{C} 20: 4 \omega 6$ relative content [3].

\section{Interrelation Between Liver and Brain C22:603}

The present experiments also provided information on the possible link between the $\mathrm{C} 22: 6 \omega 3$ content of liver versus brain phospholipids (Table 4). A highly significant positive correlation $(\mathrm{r}=+0.5792 ; \mathrm{n}=47 ; \mathrm{p}<0.001)$ between these two variables was observed in the 47 rats examined in this study (Fig. 6). This reflected mostly a group effect, however, no significant positive correlation between any- more observed between the $\mathrm{C} 22: 6 \omega 3$ content of liver and brain phospholipids in either the 23 control animals $(\mathrm{r}=+$ $0.2844 ; \mathrm{n}=23$; $\mathrm{p}>0.1$ ) or $12 \omega 3 \mathrm{D}$ rats exposed to the flaxseed oil-enriched diet $(\mathrm{r}=-0.6213 ; \mathrm{n}=12 ; \mathrm{p}<0.05)$. A significant positive correlation between these two variables $(r=$ $+0.6844 ; \mathrm{n}=12 ; \mathrm{p}<0.02$ ) only persisted in the $12 \omega 3 \mathrm{D}$ rats examined during the first 7 months of the present experiments, i.e. when they were exposed to the sunflower oilcontaining diet. These findings are consistent with the view that, in the absence of any dietary supply of long-chain polyunsaturated $\omega 3$ fatty acids, the brain phospholipid content in C22:6 $\omega 3$ reflects its synthesis in the liver and further supply to the brain via circulating lipids [14-16].

Noticeably, in the overall comparison between liver and brain phospholipid C22:6 63 content, 17 out of 18 xy products yielded null or negative values in the animals given access to a flaxseed oil-enriched diet, as distinct from only 2 out of 29 xy products in the other rats. Thus, in these two groups of rats, such xy products averaged, respectively $3.51 \pm 1.3310^{-4}(\mathrm{n}=18 ; \mathrm{p}<0.02$ versus zero $)$ and $+17.37 \pm$ $3.1210^{-4}(\mathrm{n}=29 ; \mathrm{p}<0.001$ versus zero $)$.

Table 4. Phospholipid C22:6ஸ3 Relative Weight Content in Liver, Plasma and Brain

\begin{tabular}{|c|c|c|c|c|}
\hline Phospholipid C22:603 Relative Weight Content (\%) & Liver & Plasma & Brain & (n) \\
\hline \multicolumn{5}{|l|}{$\underline{\text { Fed female control and second-generation } \omega 3 \mathrm{D}(2 \mathrm{G}-\omega 3 \mathrm{D}) \text { rats }}$} \\
\hline Control A & $14.6 \pm 0.6$ & $7.7 \pm 0.3$ & $26.8 \pm 2.6$ & (4) \\
\hline Control B & $15.4 \pm 0.6$ & $8.2 \pm 0.3$ & $22.7 \pm 0.7$ & $(12)$ \\
\hline $2 \mathrm{G}-3 \omega \mathrm{D}, 8-9$ week-old & $1.3 \pm 0.0$ & $0.7 \pm 0.0$ & $3.4 \pm 0.1$ & (6) \\
\hline $2 \mathrm{G}-3 \omega \mathrm{D}, 15-16$ week-old & $1.7 \pm 0.0$ & $0.8 \pm 0.0$ & $4.8 \pm 0.2$ & (6) \\
\hline $2 \mathrm{G}-3 \omega \mathrm{D}, 22-23$ week-old & $1.9 \pm 0.1$ & $0.9 \pm 0.0$ & $5.6 \pm 0.2$ & $(6)$ \\
\hline \multicolumn{5}{|c|}{ Fed female control and $\omega 3 \mathrm{D}$ rats, 6 week-old at the onset of the experiments } \\
\hline 3 months soya (control) & $17.9 \pm 0.7$ & & $25.3 \pm 0.6$ & $(6)$ \\
\hline 7 months soya (control) & $16.3 \pm 0.8$ & & $24.1 \pm 1.0$ & $(5)$ \\
\hline 7 months soya $+4-5$ weeks soya-enriched & $15.2 \pm 0.7$ & & $22.7 \pm 0.5$ & $(6)$ \\
\hline 7 months soya $+4-5$ weeks flaxseed-enriched & $13.9 \pm 0.9$ & & $21.9 \pm 1.1$ & $(6)$ \\
\hline 3 months sunflower $(\omega 3 \mathrm{D})$ & $4.3 \pm 0.3$ & & $20.3 \pm 0.6$ & (6) \\
\hline 7 months sunflower $(\omega 3 \mathrm{D})$ & $3.5 \pm 0.2$ & & $16.8 \pm 0.5$ & $(6)$ \\
\hline 7 months sunflower +2 weeks flaxseed-enriched & $15.3 \pm 0.6$ & & $19.2 \pm 0.4$ & (6) \\
\hline 7 months sunflower $+4-5$ weeks flaxseed-enriched & $15.0 \pm 1.2$ & & $20.3 \pm 0.6$ & (6) \\
\hline
\end{tabular}




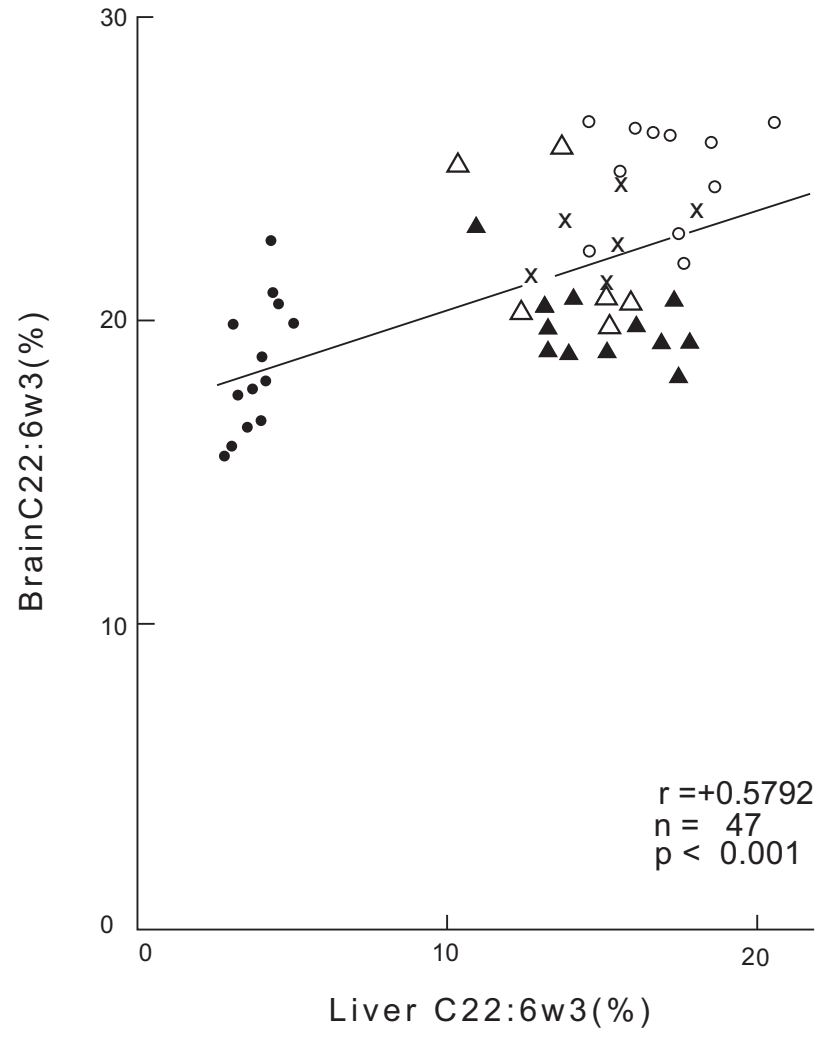

Fig. (6). Correlation between the absolute values for the liver and brain phospholipid C22:6 $\omega 3$ relative weight content in the 11 control animals (open circles) and $12 \omega 3 \mathrm{D}$ rats (closed circles) examined during the first 7 months of the present experiments, on one hand, and the 6 control rats eventually exposed for 4-5 weeks to either a soybean oil-enriched diet (crosses) or a flaxseed oilenriched diet (open triangles) and $12 \omega 3 \mathrm{D}$ rats also eventually exposed for 2 to 4-5 weeks to a flaxseed oil-enriched diet (closed triangles). The oblique line corresponds to the correlation line (with a $\sqrt{\Sigma y^{2} / \Sigma x^{2}}$ slope).

Such a situation was apparently largely attributable to differences in the time course of changes in the liver versus brain phospholipid $\mathrm{C} 22: 6 \omega 3$. Indeed, in good agreement with the concept of a transfer of C22:6 $\omega 3$ from the liver to the brain in $\omega 3 \mathrm{D}$ rats, there was a delay in the normalization of the $\mathrm{C} 22: 6 \omega 3$ relative weight content of brain phospholipids, when compared to that of liver phospholipids. Thus, in the $12 \omega 3 \mathrm{D}$ rats exposed to the flaxseed oil-enriched diet the mean brain phospholipid C22:6 $\omega 3$ content $(19.7 \pm 0.4 \%$; $n=$ 12) remained significantly lower $(\mathrm{p}<0.001)$ than that otherwise found in the 23 control animals $(23.5 \pm 0.5 \% ; n=23)$, despite a comparable C22:6 $\omega 3$ content $(\mathrm{p}>0.39)$ in the liver phospholipids of these $\omega 3 \mathrm{D}$ rats $(15.1 \pm 0.6 \% ; \mathrm{n}=12)$ and control animals $(15.8 \pm 0.5 \% ; \mathrm{n}=23)$. More precisely, whilst the brain phospholipid C22:6 $\omega 3$ content of the $6 \omega 3 \mathrm{D}$ rats exposed for only 2 weeks to the flaxseed oil-enriched diet $(19.2 \pm 0.4 \% ; \mathrm{n}=6)$ remained significantly lower $(\mathrm{p}<$ $0.005)$ than that found at a comparable time in the control animals $(22.9 \pm 0.8 \% ; n=11)$, as estimated from the measurements made just before and after exposure for 4-5 weeks of such control animals to a flaxseed oil-enriched diet, no significant difference $(\mathrm{p}>0.2)$ was anymore observed between control $(21.8 \pm 1.0 \% ; n=6)$ and $\omega 3 \mathrm{D}$ rats $(20.3 \pm 0.6$
$\% ; \mathrm{n}=6)$ when they were both exposed for 4-5 weeks to their respective flaxseed oil-enriched diets.

A situation comparable to that just described prevailed in second-generation $\omega 3 \mathrm{D}$ rats. Thus, in 18 second-generation $\omega 3 \mathrm{D}$ rats, a significant correlation $(\mathrm{r}=+0.6633 ; \mathrm{n}=18 ; \mathrm{p}<$ $0.005)$ was observed between the absolute values for the liver and brain $\mathrm{C} 22: 6 \omega 3$ relative weight content. In both the study of second-generation $\omega 3 \mathrm{D}$ rats and in the present study, two to three subgroups of $\omega 3 \mathrm{D}$ rats with increasing age were examined. In order to rule out any group effect, all individual data recorded within each subgroup were normalized relative to the mean value found in the same subgroup. Even under these most stringent analytical conditions, a highly significant positive correlation $(\mathrm{r}=+0.5200 ; \mathrm{n}=30$; $\mathrm{p}<0.006)$ still prevailed between liver and brain phospholipid C22:603 relative weight content (Fig. 7). It should be stressed that such a correlation refers to individual data with quite modest variation coefficients ( $\mathrm{SD} /$ mean) not exceeding $8.5 \pm 1.4 \%(\mathrm{n}=2)$, all except one out of 60 individual measurements remaining within the range of $15 \%$ (brain) or $20 \%$ (liver) above and below mean value.

\section{Possible Role of Plasma Phospholipids in the Transfer of C22:6w3 from Liver to Brain}

In these $\omega 3 \mathrm{D}$ rats, the postulated transfer of $\mathrm{C} 22: 6 \omega 3$ synthesized in hepatocytes from the liver to the brain is likely to be mediated mainly by circulating phospholipids (Fig. 8). Indeed, in the second-generation $\omega 3 \mathrm{D}$ rats and corresponding control animals significant positive correlations

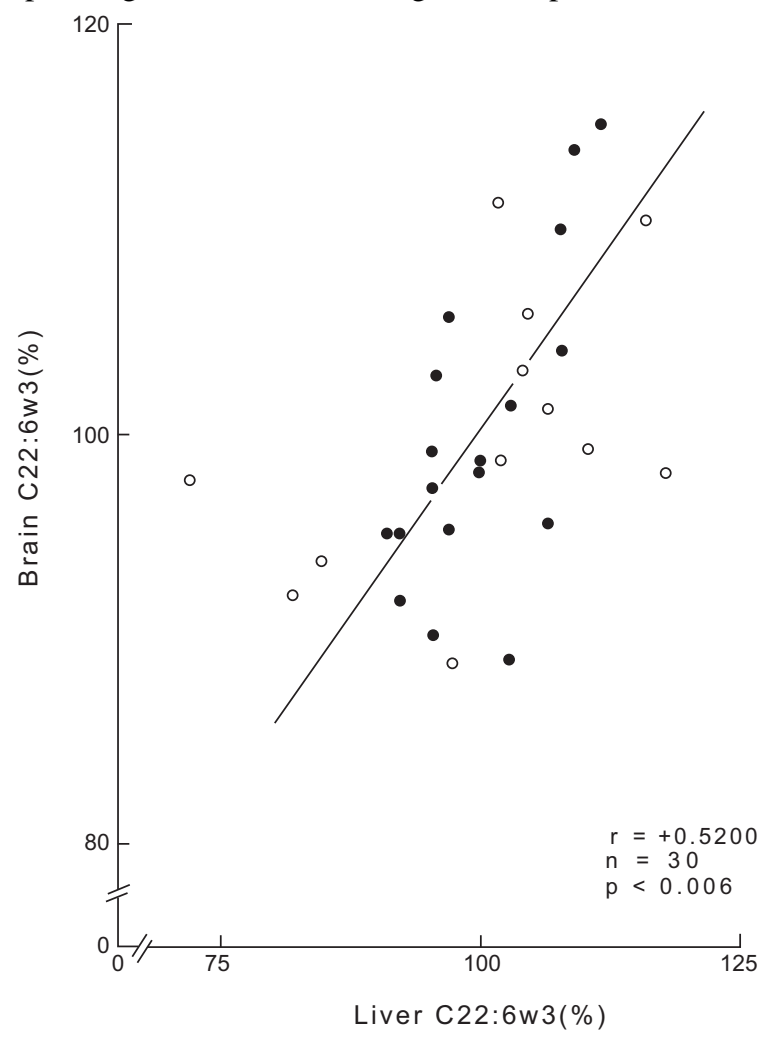

Fig. (7). Correlation between the normalized values for the liver and brain phospholipid C22:6 03 relative weight content in zerogeneration (open circles) and second-generation (closed circles) $\omega 3$-depleted rats. The oblique line corresponds to the correlation line (with a $\sqrt{\Sigma y^{2} / \Sigma x^{2}}$ slope). 
were found between either the absolute values $(\mathrm{r}=+0.9935$; $\mathrm{n}=34 ; \mathrm{p}<0.001)$ or normalized values $(\mathrm{r}=+0.7793 ; \mathrm{n}=$ $34 ; \mathrm{p}<0.001)$ for the relative weight content of $\mathrm{C} 22: 6 \omega 3$ of liver and plasma phospholipids. A highly significant correlation was also found in the same rats between the absolute values for the C22:6 63 relative weight content of plasma and brain phospholipids $(\mathrm{r}=+0.9413 ; \mathrm{n}=34$; $\mathrm{p}<0.001)$. In terms of normalized values, however, a significant positive correlation between the $\mathrm{C} 22: 6 \omega 3$ relative content of plasma and brain phospholipids only persisted in the $18 \omega 3 \mathrm{D}$ rats $(\mathrm{r}$ $=+0.7032 ; \mathrm{n}=18 ; \mathrm{p}<0.002)$. The latter finding further supports the existence of a close link between these two variables at the individual level at least when the diet is deprived of long-chain polyunsaturated $\omega 3$ fatty acids.

\section{Possible Role of Plasma Triglycerides in the Transfer of

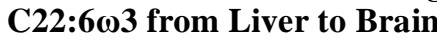

A possible contributive role of plasma triglycerides in the transfer of $\mathrm{C} 22: 6 \omega 3$ from the liver to the brain was also considered. In this respect, the brain triglycerides were not considered, however, since a sizeable amount of $\mathrm{C} 22: 6 \omega 3$ in these lipids was only detected in 5 out of 34 animals in the series of experiments dealing with second-generation $\omega 3 \mathrm{D}$ rats and the corresponding control animals, and in 4 out of 47 rats in the series of experiments dealing with the rats exposed to several distinct diets from the $6^{\text {th }}$ week after birth onwards. It should nevertheless be mentioned that the mean values for the $\mathrm{C} 22: 6 \omega 3$ relative weight content of brain triglycerides in the fed female control rats never exposed to an $\omega 3$-deficient diet were not significantly different from one another in the former series of experiments $(3.5 \pm 1.4 \% ; \mathrm{n}=$ $16)$, in the latter series of experiments $(2.8 \pm 1.4 \% ; n=23)$ and in a further independent series of experiments $(4.3 \pm 2.6$ $\% ; n=4)$, with an overall mean value of $3.2 \pm 0.9 \%(n=$ 43).

In the former series of experiments, sizeable amounts of C22:6 $\omega 3$ were only detected in the liver and plasma triglyc- erides of control animals, but not so in the liver or plasma triglycerides of $\omega 3 \mathrm{D}$ rats. A highly significant correlation was found between the absolute values for the liver and plasma triglyceride $\mathrm{C} 22: 6 \omega 3$ relative weight content $(\mathrm{r}=+$ $0.9530 ; \mathrm{n}=34 ; \mathrm{p}<0.001)$. In the 16 control animals, a significant positive correlation also prevailed between the normalized values for the same variables $(r=+0.6635 ; n=16$; $\mathrm{p}<0.007)$

In the same former series of experiments, a highly significant positive correlation was also found between the C22:6 133 content of liver triglycerides and brain phospholipids $(\mathrm{r}=+0.8923 ; \mathrm{n}=34 ; \mathrm{p}<0.001)$. This corresponded to a group effect. Indeed, in the 16 control animals, which were the sole animals to display sizeable amounts of C22:6 13 in liver triglycerides, no correlation was anymore observed between the normalized values for the same two variables $(r$ $=-0.0921 ; \mathrm{n}=16 ; \mathrm{p}>0.1)$.

Likewise, in the series of experiments conducted in the rats exposed to various diets from the $6^{\text {th }}$ week after birth onwards, a significant positive correlation was found between the absolute values for the C22:603 content of liver triglycerides and brain phospholipids $(\mathrm{r}=+0.7266 ; \mathrm{n}=47 ; \mathrm{p}$ $<0.001$ ), but no more so in the 35 rats with sizeable amounts

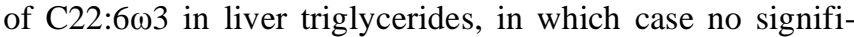
cant correlation was found between the normalized values for the two variables under consideration $(\mathrm{r}=+0.0382 ; \mathrm{n}=$ $35 ; \mathrm{p}>0.1)$.

The relationship between the $\mathrm{C} 22: 6 \omega 3$ content of plasma triglycerides and brain phospholipids was essentially comparable to that just described in the case of liver triglycerides and brain phospholipids. Thus, in the series of experiments dealing with second-generation $\omega 3 \mathrm{D}$ rats and corresponding control animals, a highly significant positive correlation was found between the absolute values for the two variables under consideration $(r=+0.9054 ; n=34 ; p<0.001)$. Such was no more the case, however, for the normalized values of the
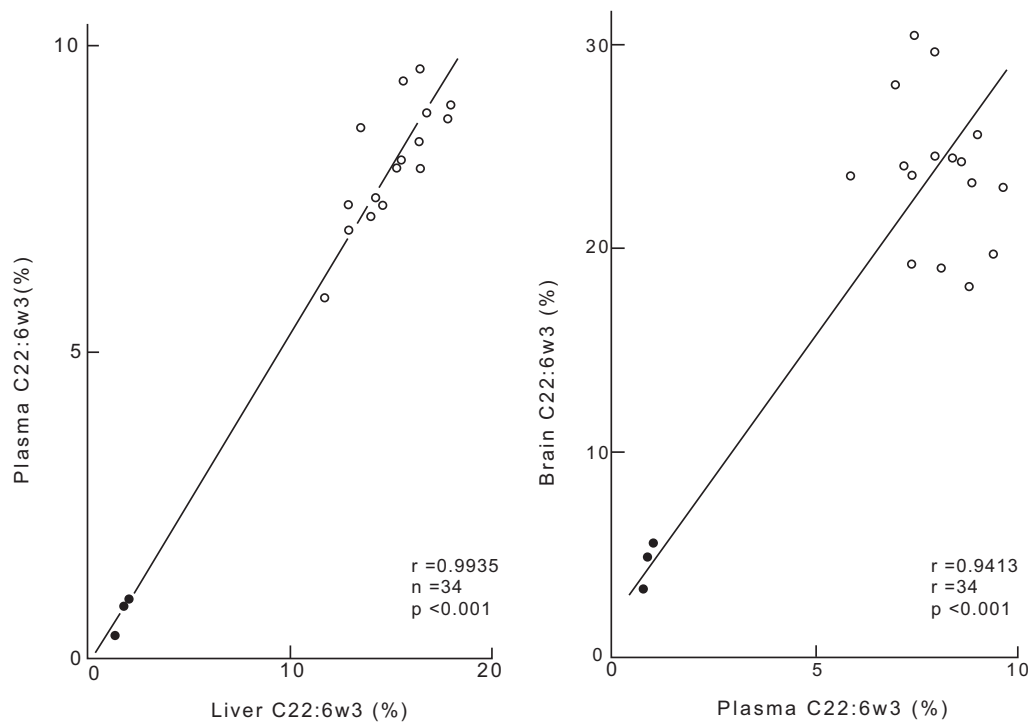

Fig. (8). Correlation between the liver and plasma (left) and between the plasma and brain (right) C22:6 03 relative weight content of phospholipids in 16 control rats (open circles) and 18 second-generation $\omega 3 \mathrm{D}$ rats (closed circles). Only the mean values recorded in 3 subgroups of $6 \omega 3 \mathrm{D}$ rats each with increasing ages (8-9, 15-16 and 22-23 weeks) are indicated, in order to avoid the superposition of individual measurements. The oblique lines correspond to the correlation lines (with a $\sqrt{\Sigma y^{2} / \Sigma x^{2}}$ slope). 
same variables in the 16 control animals, i.e. the sole animals to contain detectable amounts of $\mathrm{C} 22: 6 \omega 3$ in plasma triglycerides $(\mathrm{r}=-0.3992 ; \mathrm{n}=16 ; \mathrm{p}>0.1)$.

Taken as a whole, these findings suggest a close link between the $\mathrm{C} 22: 6 \omega 3$ content of liver and plasma triglycerides, but argue against any significant contribution of liver and/or plasma triglycerides to the supply of $\mathrm{C} 22: 6 \omega 3$ to brain phospholipids.

\section{Liver Steatosis, Adipose Tissue Mass, Body Weight Gain and Food Intake}

As expected from the results of prior studies conducted in second-generation $\omega 3 \mathrm{D}$ rats $[11,17-20]$, the rats exposed for 3 to 7 months to an $\omega 3$-deprived diet developed liver steatosis, visceral obesity and insulin resistance $[1,2]$.

In the two present sets of experiments, the total fatty acid content of liver triglycerides remained significantly higher in the $\omega 3$-depleted rats than in the control animals both eventually exposed for 4-5 weeks to a flaxseed oil-enriched diet [1, 8]. As a matter of fact, in the former animals, such a variable progressively increased during exposure of the $\omega 3$-depleted rats to the flaxseed oil-enriched diet. Comparable increases were observed over the same period for both body weight and parametrial adipose tissue mass [2].

The second set of experiments in the present study aimed mainly at identifying the possible determinants of such increases. Hence, attention was paid to the changes in food intake occurring after the switch in diet $[8,9]$.

Two procedures were followed to estimate possible differences in food intake between the 3 groups of rats examined in this second set of experiments. First, the food intake was measured over the 7 days before and 14 days after the switch in diet over successive periods of 1-4 days [9]. This allowed for instance to assess the increment in food intake $(\mathrm{df}=12)$ after the switch in diet, and to express it relative to the mean value recorded theretofore. In the second procedure, advantage was taken from the increase in either the total fatty acid content of liver triglycerides or their content in either $\mathrm{C} 18: 3 \omega 3$ or $\mathrm{C} 22: 6 \omega 3$ [8]. The results obtained with the latter 3 criteria were in fair agreement with those derived from the direct measurement of food intake. Thus, the comparison between the relative magnitude of the switchinduced increase in food intake and our indirect assessment yielded the same hierarchy in mean values (control rats switched to a flaxseed oil-enriched diet < control rats switched to a soybean oil-enriched diet $<\omega 3 \mathrm{D}$ rats switched to a flaxseed oil-enriched diet), the results of the indirect assessment in the 3 groups of rats representing $97.5 \pm 15.6 \%$ ( $\mathrm{df}=57$ ) of those corresponding mean values obtained by the direct measurement of food intake.

The results of food intake direct measurements obtained in the 3 groups of rats also allowed to document that the switch-induced increment in the $\omega 3 \mathrm{D}$ rats eventually exposed to the flaxseed oil-enriched diet were not only more pronounced but also more sustained than in the other two groups of animals. Nevertheless, even in the former group of rats, the time course for changes in food intake after the switch in diet indicated that they were about thrice higher during the first 2 weeks after the switch in diet than during the ensuing 3 weeks, this time-related pattern being superimposable to that characterizing the time course for the increase in body weight in the same group of rats [2].

Last, as illustrated in Fig. (9), there was a tight correlation between our indirect estimation of the increase in food intake and the overall gain in body weight over the last 3 weeks of the present experiments, this suggesting the absence of any major difference in the 3 groups of rats, in terms of the energetic efficiency ( $\Delta$ in body weight/ $\Delta$ in caloric intake) of their respective diets.

Three mechanisms were proposed to possibly account for these changes in food intake. First, in all 3 groups of rats, the increase in the total lipid content of the diet from $5 \%$ before to $10 \%$ after the switch in diet could account, in part at least, for the increase in food intake, in fair agreement with a prior observation [21]. Second, a flaxseed oil dietary self selection in the $\omega 3 \mathrm{D}$ rats, which indeed slowly develop a robust preference for consumption of an w3-rich diet, should not be ignored [22]. In the same line of thinking, the more pronounced and more sustained increase in food intake observed in the control rats exposed to a soya oil-enriched diet, as distinct from flaxseed oil-enriched diet, could conceivably involve a process in mirror image of the induction of flaxseed dietary self selection in $\omega 3 \mathrm{D}$ rats. Last, in the $\omega 3 \mathrm{D}$ rats, an orexigenic effect attributable to the brain accumulation of

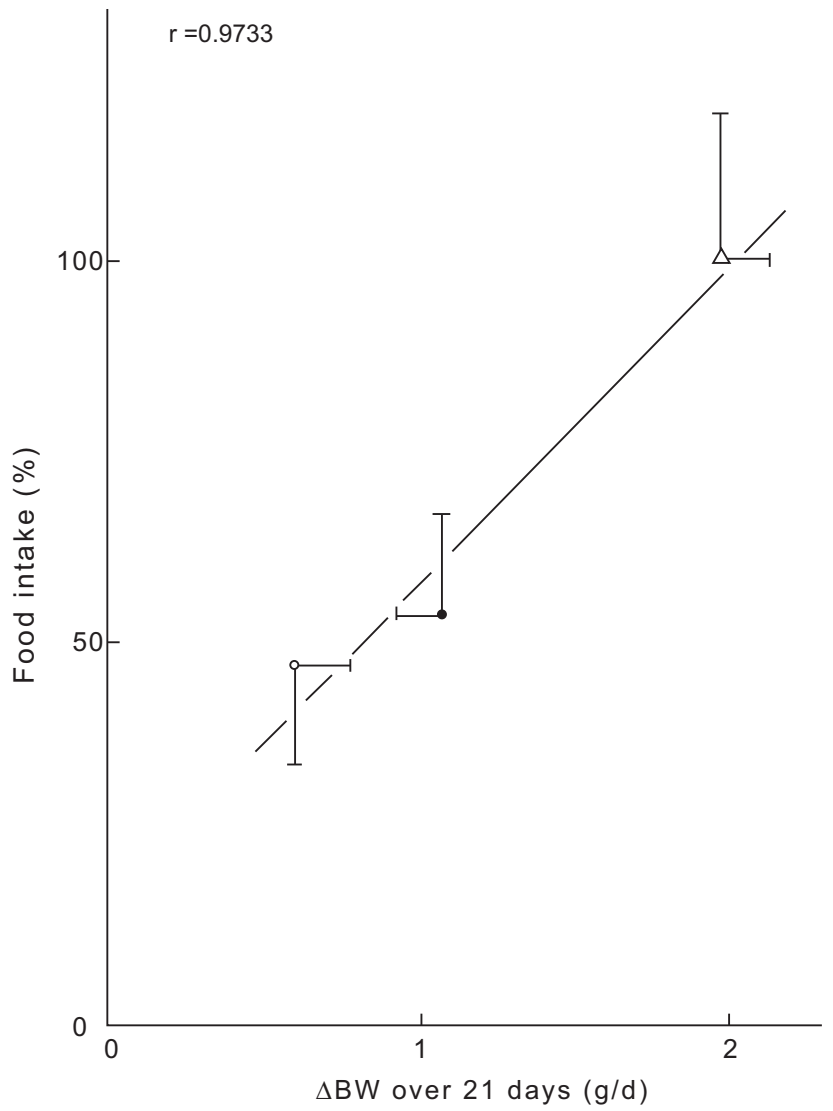

Fig. (9). Correlation between the mean values $( \pm S E M ; n=6$ in each case) for the estimated food intake (expressed relative to the mean value found in the $\omega 3 \mathrm{D}$ rats eventually exposed to a flaxseed oil-enriched diet) and the observed gain in body weight over a period of 21 days (expressed in g/day) in control rats eventually exposed to either a soya (closed circles) or flaxseed oil-enriched diet (open circles) and $\omega 3 \mathrm{D}$ rats also exposed to a flaxseed oil-enriched diet (open triangles). 
long-chain polyunsaturated $\omega 3$ fatty acids and already documented by a number of prior studies [23-26] may well participate to the increase in food intake during the late period of exposure to the flaxseed oil-enriched diet.

Taken as a whole, these findings draw attention to the idea that, in order to correct both the depletion in $\omega 3$ fatty acids and its undesirable consequences, such as liver steatosis and visceral obesity, it may be necessary to combine the dietary supply of long-chain polyunsaturated $\omega 3$ fatty acids with a suitable control of food intake, in both qualitative and quantitative terms.

\section{CONCLUSION}

This last report in the present series draws mainly attention to differences between liver or intestine versus brain in terms of the time course for the alteration of the fatty acid profile of phospholipids during successive exposure of rats to diets first deprived of and thereafter enriched with longchain polyunsaturated $\omega 3$ fatty acids. It also provides support to the view that circulating phospholipids play an essential role, at least in $\omega 3 \mathrm{D}$ rats, in the transfer from liver to brain of

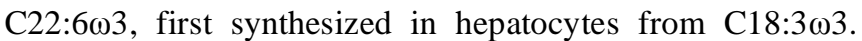
Last, it emphasizes the need to control the intake of both $\omega 3$ fatty acids and lipids in the care of subjects depleted in such long-chain polyunsaturated $\omega 3$ fatty acids.

\section{ACKNOWLEDGEMENTS}

This study was supported by a grant from the Belgian Foundation for Scientific Medical Research (3.4574.07), and the Convention 5459 (Project WALNUT-20) from the Région Wallonne (Namur, Belgium). We are indebted to C. Demesmaeker for secretarial help.

\section{REFERENCES}

[1] Malaisse WJ, Bulur N, Zhang Y, et al. The metabolic syndrome of $\omega 3$-depleted rats. I. Liver data. Int J Mol Med 2009; 24: 111-23.

[2] Sener A, Zhang Y, Bulur N, Louchami K, Malaisse WJ, Carpentier YA. The metabolic syndrome of $\omega 3$-deficient rats. II. Body weight, adipose tissue mass and glycemic homeostasis. Int $\mathbf{J}$ Mol Med 2009; 24: 125-9.

[3] Portois L, Hacquebard M, Malaisse WJ, Carpentier YA. The metabolic syndrome of $\omega 3$-depleted rats. III. Brain phospholipids. Int J Mol Med 2009; 24: 269-78.

[4] Hacquebard M, Portois L, Malaisse WJ, Carpentier YA. The metabolic syndrome of $\omega 3$-depleted rats. IV. Intestinal phospholipid $\omega 3$ fatty acids. Int J Mol Med 2009; 24: 859-65.

[5] Hacquebard M, Portois L, Malaisse WJ, Carpentier YA. The metabolic syndrome of $\omega 3$-depleted rats. V. Intestinal phospholipid $\omega 6$ fatty acids. Int J Mol Med 2009; 24: 867-75.

[6] Carpentier YA, Hacquebard M, Portois L, Malaisse WJ. The metabolic syndrome of $\omega 3$-depleted rats. VI. Intestinal phospholipid saturated and monodesaturated fatty acids. Int J Mol Med 2009 ; 25: $171-81$

[7] Malaisse WJ, Portois L, Hacquebard M, Carpentier YA. The metabolic syndrome of $\omega 3$-depleted rats. VII. Intestinal phospholipid $\omega 9$ fatty acids. Metab Funct Res Diab 2009; 2: 55-8.
[8] Malaisse WJ, Zhang Y, Bulur N, et al. The metabolic syndrome of $\omega 3$-depleted rats. VIII. Dietary lipid-induced liver steatosis. Open Physiol J 2010; 3: 1-9.

[9] Zhang Y, Bulur N, Louchami K, et al. The metabolic syndrome of w3-depleted rats. IX. Food intake. Open Physiol J 2010; 3: 10-5.

[10] Malaisse WJ, Portois L, Sener A, Carpentier YA. Brain phospholipid and triglyceride fatty acid content and pattern in rats depleted in long-chain polyunsaturated $\omega 3$ fatty acids. Trends Cell Mol Biol 2007; 2: 69-76.

[11] Louchami K, Zhang Y, Oguzhan B, et al. Rapid changes in liver lipid composition and pancreatic $\mathrm{K}^{+}$handling and secretory behaviour provoked by the intravenous administration of a medium-chain triglyceride:fish oil emulsion to long-chain polyunsaturated $\omega 3$ fatty acid-depleted rats. Int J Mol Med 2006; 18: 1047-55.

[12] Carpentier YA, Portois L, Sener A, Malaisse WJ. Correlation between liver and plasma fatty acid profile of phospholipids and triglycerides in rats. Int $\mathrm{J}$ Mol Med 2008; 22: 255-62.

[13] Malaisse WJ, Hacquebard M, Portois L, Sener A, Carpentier YA. Regulation of $\Delta 9$-desaturase activity in the liver of rats depleted in long-chain polyunsaturated $\omega 3$ fatty acids. Trends Cell Mol Biol 2010; in press.

[14] Igarashi M, DeMar JC Jr, Ma K, Chang L, Bell JM, Rapoport SI. Upregulated liver conversion of alpha-linolenic acid to docosahexaenoic acid in rats on a 15 week n-3 PUFA-deficient diet. J Lipid Res 2007; 48: 152-64.

[15] Igarashi M, DeMar JC Jr, Ma K, Chang L, Bell JM, Rapoport SI. Docosahexaenoic acid synthesis from alpha-linolenic acid by rat brain is unaffected by dietary n-3 PUFA deprivation. J Lipid Res 2007; 48: 1150-8.

[16] Igarashi M, Ma K, Chang L, Bell JM, Rapoport SI. Dietary n-3 PUFA deprivation for 15 weeks upregulates elongase and desaturase expression in rat liver but not brain. J Lipid Res 2007; 48: 2463-70.

[17] Oguzhan B, Sancho V, Acitores A, et al. Alteration of adipocyte metabolism in $\omega 3$ fatty acid-depleted rats. Horm Metab Res 2006; 38: 789-98.

[18] Carpentier YA, Peltier S, Portois L, Sebedio JL, Leverve X, Malaisse WJ. Rapid reduction of liver steatosis in $\omega 3$-depleted rats injected with a novel lipid emulsion. Horm Metab Res 2008; 40: 8759.

[19] Oguzhan B, Zhang Y, Louchami K, et al. Pancreatic islet function in $\omega 3$ fatty acid-depleted rats. Glucose metabolism and nutrientstimulated insulin release. Endocrine 2006 ; 29: 457-66.

[20] Cancelas J, Prieto PG, Villanueva-Peñacarrillo ML, et al. Glucose intolerance associated to insulin resistance and increased insulin secretion in rats depleted in long-chain polyunsaturated $\omega 3$ fatty acids. Horm Metab Res 2007; 39: 823-5.

[21] Cani PD, Neyrinck AM, Maton N, Delzenne NM. Oligofructose promotes satiety in rats fed a high-fat diet: involvement of glucagon-like peptide-1. Obes Res 2005; 13: 1000-7.

[22] Dunlap S, Heinrichs SC. Neuronal depletion of omega-3 fatty acids induces flax seed dietary self-selection in the rat. Brain Res 2009; 1250: 113-9.

[23] Barber MD, Ross JA, Voss AC, Tisdale MJ, Fearon KC. The effect of an oral nutritional supplement enriched with fish oil on weightloss in patients with pancreatic cancer. Br J Cancer 1999; 81: 80-6.

[24] Brown TT, Zelnik DL, Dobs AS. Fish oil supplementation in the treatment of cachexia in pancreatic cancer patients. Int J Gastrointest Cancer 2003; 34: 143-50.

[25] Ramos EJ, Romanova IV, Suzuki S, et al. Effects of omega-3 fatty acids on orexigenic and anorexigenic modulators at the onset of anorexia. Brain Res 2005; 1046: 157-64

[26] Goncalves CG, Ramos EJ, Romanova IV, Suzuki S, Chen C, Meguid MM. Omega-3 fatty acids improve appetite in cancer anorexia, but tumor resecting restores it. Surgery 2006; 139: 202-8.

This is an open access article licensed under the terms of the Creative Commons Attribution Non-Commercial License (http://creativecommons.org/licenses/ by-nc/3.0/) which permits unrestricted, non-commercial use, distribution and reproduction in any medium, provided the work is properly cited. 